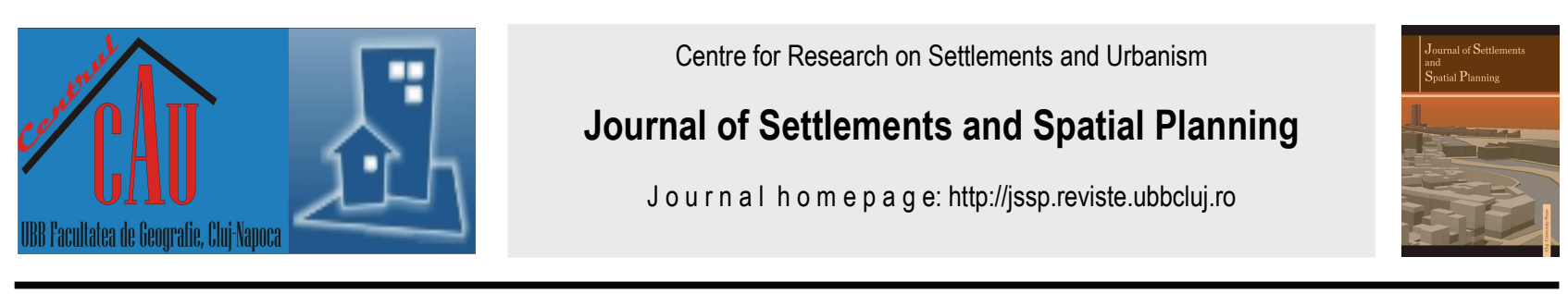

\title{
GIS-Based Kernel Analysis for Tourism Flow Mapping
}

\author{
Mărgărit-Mircea NISTOR ${ }^{1 *}$, Alexandru-Sabin NICULA², 3, Ştefan DEZSI3, Dănuţ PETREA4, \\ Shankar Acharya KAMARAJUGEDDA5, Iulius-Andrei CAREBIA6 \\ *Corresponding author \\ ${ }^{1}$ Earth Research Company, Department of GIS and Cartography, Cluj-Napoca, ROMANIA \\ ${ }^{2}$ Romanian Academy, National Institute for Economic Research "Costin C. Kiritescu" of the Romanian Academy, Centre for Mountain \\ Economy (CE-MONT), Vatra Dornei, ROMANIA \\ ${ }_{3}$ Babeş-Bolyai University, Faculty of Geography, Centre for Research on Settlements and Urbanism, Cluj-Napoca, ROMANIA \\ ${ }_{4}$ Babeş-Bolyai University, Faculty of Geography, Cluj-Napoca, ROMANIA \\ ${ }_{5}$ Nanyang Technological University, Interdisciplinary Graduate School, Singapore, SINGAPORE \\ ${ }^{6}$ German European School, Singapore, SINGAPORE \\ E-mail: rendddel@yahoo.com, sabin.nicula@gmail.com, stefan.dezsi@ubbcluj.ro,danut.petrea@ubbcluj.ro, \\ shankaracharyaoo1@gmail.com, icarebia@gmail.com \\ DOI: 10.24193/JSSP.2020.2.07 \\ https://doi.org/10.24193/JSSP.2020.2.07
}

K e y w o r d s: tourism flow, spatiality, international arrivals, GIS mapping, Romania

\begin{abstract}
A B S T R A C T
The variation of tourism flow and its spatial representation are indispensable for transport companies, accommodation facilities and future estimations regarding the international arrivals. The major implication for tourism flow mapping is related to the country of origin of tourists, their liquid assets, and tourism statistical database. The approach of tourism flow mapping representation, at least using lines and density, should be based on the spatial characteristics of the objects. In this study, the database consisting of international arrivals in different cities of Romania was used as an example. Thus, GIS-based Kernel density of the tourists' flow was proposed. To illustrate the international demand, data on arrivals for 33 countries over the period 2015-2017 were used. 'XY To Line' and 'Kernel Density' functions served to create the convergence lines between the origin countries and Romania. The very high density was found for the European countries with an increase of 13\% and 25\% between 2015 and 2016, as well as between 2015 and 2017. Map analysis indicated an increase of the density area by $0.7 \%$ for 2016 and 1.7\% for 2017. The proposed methods, including lines and density, contribute to the mapping of the flow of the international arrivals in Romania.
\end{abstract}

\section{INTRODUCTION}

Nowadays, the number of tourists of different nationalities is much higher than in the last decades. The modern transport infrastructure and a large variety of accommodation facilities, as well as travel agencies and their services contribute to the intensity of international tourism. Moreover, the development of new software and online programs, which allow for better ways to analyse tourism data, contribute to achieving good results regarding tourism flow, and also help in the future modelling of the tourism phenomenon.
Tourism flow assessment represents a very suitable way to analyse tourism flow towards the destination. In addition, through such analysis, the characteristics of tourists, motivational factors, accommodation infrastructure, types of tourism, and other factors could be considered. Hall and Page (2009) indicate the progress of 'Tourism Management' Journal considering the geographical studies on tourism. One of the most interesting issues discussed in their paper refers to the development of Geographical Information Systems (GIS) which contributes to the analysis of data at spatial scale. Thus, the role of GIS technology in Applied Geography and decision-making in tourism 
becomes a very useful tool for information processing and problem-solving (Butler, 1992; Hall and Page, 2009). Important studies regarding the exploratory space-time analysis and spatial econometric approach of tourism flows was made by Yang and Wong in 2012. They analysed domestic tourism flows to 341 cities in China using physical infrastructure factors and tourist attractions. However, the representation at spatial scale is missing from all the above mentioned models. As an exception, for China, the international tourist arrivals over 1978-2009 were analysed through exploratory spatial data analysis by Xing-zhu and Qun (2013). In their study, the spatial clustering of inbound tourism flows by the "Global Moran's I" was analysed.

Fourie and Santana-Gallego (2011), Santeramo and Morelli (2016) studied tourism flow through gravity models. Thus, econometric modelling contributes to wide derived data from the obtained results (Hall, 2012). In addition, quantile regression is often used to estimate tourism demand segmentation (Koenker, 2005; Santeramo and Morelli, 2016). Zieba (2016) investigated the impact of tourism flow on demand for theatres in Austria, between 1972 and 2011. The author used the empirical insights based on statistical data (i.e. domestic trips and foreign trips, income per resident, seats on offer etc.) at NUTS 2 and NUTS 3 territorial levels. Carey et al. (2013) used time series analysis to explore the extent to which the opening of the Museum of New Zealand in 1998 contributed to tourism growth in Wellington. In their study, the econometric evaluation for the cultural attraction and visitors based on tourism data (i.e. number of guest arrivals, overnights, and occupancy rates) was used into an econometric regression.

In the European regions, tourism flow was determined by Marrocu and Paci (2011) using local companies. The tourism flow from China, Japan and South Korea during 2005-2017 was studied by Jin et al. (2019). Tourism flow was assessed considering the impact of political, economic and environmental crisis factors. Andraz and Rodrigues (2016) carried out tourism flow monitoring and destination during 19872015 in Portugal. They analysed domestic and international demand cycles dynamics using "economic climate tracer" tool and they found that tourism flows from countries like Germany, Netherlands and the UK decreased, whilst, in contrast, the tourism flow trend from Spain increased. A case study of tourism flow in the Forbidden City was carried out using the Baidu Index (Huang et al. 2017). This index represents an important engine for the free massive data analysis and it is based on Baidu web search. Liu et al. (2019) analysed the spatial-temporal response patterns of tourism flow to the Tianmu Lake from China. They have used search volume index (SVI) and Granger causality tests to analyse the relationship between daily tourist arrivals and search indexes from 13 sites.
Light and Dumbrăveanu (1999) analysed the post-communism tourism in Romania during the 1990s, and they found a considerable decline in the international arrivals due to the political and economic instability, but also due to the poor infrastructure and services (Light and Dumbrăveanu, 1999). Even if several problematic issues are still present in the Romanian tourism industry, significant promotions were the focus of the post-communism period in the case of tourist attraction sites from Bucharest (i.e. the Parliament Palace also known as "The People's House") and the high impact brand attractiveness such as Bran Castle in Transylvania (also known as Dracula's castle) (Light, 2010). Iorio and Corsale (2010) found positive aspects of rural strategies and economic growth for the family enterprises and development of rural areas in Romania. In addition to this matter and showing a growing interest for rural tourism in Romania, the government managed this type of tourism in a better and different way by supporting families that developed rural tourism (Iorio and Corsale, 2010). Tourism attractiveness in eastern Romania was evaluated by Iațu and Bulai (2011) including the supply of inner forces and correlation between supply and demand. It was suggested by Pomeanu and Teodosiu (2012) that tourism development plans should include "economic operators, public entities, community members, research-innovation units" (Pomeanu and Teodosiu, 2012, p. 446).

A study regarding the international tourism flow in Romania at spatial scale may contribute to the specialist literature. The major objective of this paper is to assess the 'XY To Line' and 'Kernel Density' functions from the ArcGIS environment to reflect the spatiality of tourism flow. The second objective of this study is to apply these GIS functions to generate the connections and density maps of the international arrivals in Romania during the period 2015-2017. The analysis of tourism flow lines, completed by statistical data are the deliverables of the applied methodology. This kind of analysis is important for the better understanding of the international tourists' source mapping. Thus, the 'Kernel Density' lines generated in this study could be compared with the major airlines routes and further conclude if various collaborations between travel and transport agencies from origin countries and those from destination countries could be developed. In addition, the procedures used and findings are useful for the academic community in the field of tourism and transports.

\section{TOURISM VARIATION IN ROMANIA}

During the last decade, the number of tourists that visited Romania increased by $20 \%$ and most of them targeted city destinations (INS, 2018). The international demand for city tourism indicates large 
heterogeneity regarding origin and residence of visitors, showing major interest on behalf of tourists from Italy, Germany, Israel, France, United Kingdom, and the US, which account for more than $50 \%$ of the total arrivals (INS, 2017). The natural and cultural heritage of Romania is very much diversified. Located in southcentral Europe, Romania extends over the Southern Carpathians and its peripheral units (West Plain), Romanian Plain, Moldavian Plateau, Dobrogea Plateau, and the Danube Delta. Different tourism types are practiced during the entire year. However, during the last decade it was observed that, in the summer season, the number of tourists in Romania was higher than in other seasons. Since 2010, the number of overnight stays continuously increased from 15,967,100 (15.96 million) to $26,915,700$ (26.91 million). The total number of foreign tourists exceeded 2,600,00o in 2017 (World Travel \& Tourism Council, 2018), which represents a high increase for the last three decades. During the period 2015-2017, the number of international tourists increased also from 1,683,267 (1.68 million) to $2,132,135$ (2.13 million). All along, World Travel \& Tourism Council (2006) reported about $5.8 \%$ of the country workforce engaged in tourism activities, meaning an availability of approximately 485,00o tourism jobs in Romania. This fact has had a significant impact on the Romanian economy, with a contribution of US $\$ 1,782.6 \mathrm{mln}$. to the Gross Domestic Product (GDP) (World Travel \& Tourism Council, 2006). Recently, the same organization brought forward the statistics for 2017 , according to which the amount of tourism-related jobs raised to 208,500 and a total contribution to GDP was of about US\$ $11,185.7$ mln. These metrics clearly indicate a substantial development of the tourism industry during the last decade.

\section{MATERIALS AND METHODS}

\subsection{Overview of the methodology}

In this study, the spatial representation of the tourism flow was developed. Two main functions from the ArcGIS environment were used as tools for mapping. 'XY To Line' function and Kernel density were employed to process the tourism data for Romania. This procedure represents a cartographic approach that gives a solution through tourism flow mapping. Thus, the cartographic support contributes in the future to various statistics analyses (e.g. density, standard deviations, comparison with main airlines routes) or changes calculations as we are providing in this study.

\subsection{Tourism data}

Three datasets, including the number of international tourist arrivals in the Romanian cities, were analysed with regard to the period 2015-2017. Data records were published by the National Institute of Statistics in Romania (2015, 2016, and 2017) and refer to the residence and origin of tourists. International arrivals in Bucharest and other Romanian cities, except for Tulcea, were considered into the analysis of tourism flow variation. Thus, a number of international arrivals from 33 countries were collected and prepared for the spatial flow representation. In addition, data on the total number of departures was collected for the origin countries of the tourists that visited the Romanian cities during the period 2015-2017. In order to observe the tourists' behaviour, the correlation between the distance from the origin country to Romania and the departures was performed. Even if these statistics are empirical, they proved useful to find out if, at this level, there is or not a strong correlation between tourists and the distance to from the origin country to the destination.

\subsection{GIS datasets}

The vector data of the world's countries was used to create the GIS database and to process the information through the ArcGIS 10.5 environment. Tourism data on the international arrivals were uploaded into the software, and tourism flow analysis was performed considering converging flow over Romania. For these procedures, GIS datasets were pre-processed as follows: (i) raw tourism data of MS Excel file related to each international arrivals was assigned into ArcGIS attribute table by country field, (ii) the centroids and its geographical coordinates (latitude and longitude) of each country (polygon shape-files) were generated, and (iii) flow lines from the origin country of tourists over the locations in Romania were generated.

\subsection{Tourism flow lines}

Tourism flow phenomenon from the origin country to destination was analysed using GIS technology. Thus, 'Features' tools, found in 'Data Management Tools', were employed to obtain the spatial analysis of the tourists flow from 33 countries in the world to Romania during the period 2015-2017. This approach contributes to the generation of flow lines and classes of international tourist arrivals on the World Map. The results of the flow trajectories were mapped using 'XY To Line' function in the ArcMap 10.5. software.

\subsection{Kernel Density}

Based on the tourism flow lines vector data, the Kernel Density (Silverman, 1986) the determination for each data set was performed. This function combines both the distance and number of tourists for 
that particular line. Kernel Density (Silverman, 1986) is a non-parametric method to estimate the probability density function of random data. As a consequence, the mathematical function indicates that the importance of Kernel Density is much related to the values of the vector data and, through this tool, the classification of overlapped areas could be drawn.

$$
f_{h}=(x)=\frac{1}{n} \sum_{i=1}^{n}\left(\frac{n}{k}\right) K_{h}\left(x-x_{i}\right)
$$

where:

$f$ - density $f$;

$K$ - Kernel - a non-negative function;

$h>O$ - smoothing parameter called the bandwidth;

$x_{1}, x_{2}, x_{n}$ is univariate independent and identically distributed sample.

In the next step, the maximum density map for the period 2015-2017 was generated using the 'Cell Statistics' tool from Spatial Analyst. Thus, the spatial distribution of the Kernel Density map for 2015-2017 period was obtained and further analysed at spatial scale. The relative change between 2015 vs. 2017 and 2016 vs. 2017 were calculated using Eq. (2).

$$
K_{d}=\frac{K_{d i}-K_{d 1}}{K_{d 1}}
$$

where:

$K_{d}$ - Kernel density relative change

$K_{d i}$ - Kernel density i = final year (e.g. 2017)

$K_{d 1}$ - Kernel density 1 = initial year (e.g. 2015,

2016).

\section{RESULTS AND DISCUSSION}

Overall, the GIS pattern analysis indicates Europe as the main tourist source market for Romania. A total of 33 countries from which tourists came to visit the Romanian cities was observed during the period of 2015-2017. Tourists from countries like Italy, Germany, Israel, France, and the UK are most interested in the urban tourism in Romania. However, even with the long distance, the United States is included in the countries with high number of tourists visiting cities in Romania. In addition, even if it is located far from Romania, China contributed with a number of 28,869 tourists in 2017.

In 2015, the maximum number of international arrivals for city visits was attributed to Germany (203,601 arrivals), followed by Italy (172,923 arrivals), and Israel (160,590 arrivals). Denmark, Australia, and Slovenia are the countries that provided a small number of tourists in the Romanian cities, followed by other countries that were not included in 140 the analysis (less than 7,852 arrivals). Figure 1a shows the total number of international arrivals in the Romanian cities, by country. The result of the flow representation related to 2015 was mapped in Figure $1 \mathrm{~b}$ using the ' $\mathrm{XY}$ To Line' function in the ArcMap 10.5 software.

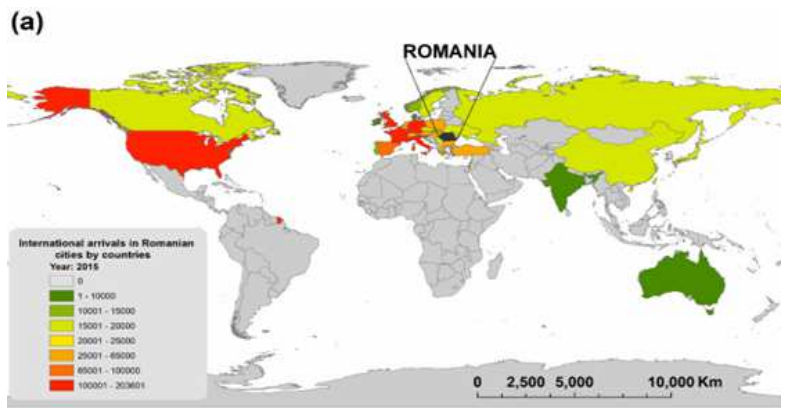

(b)

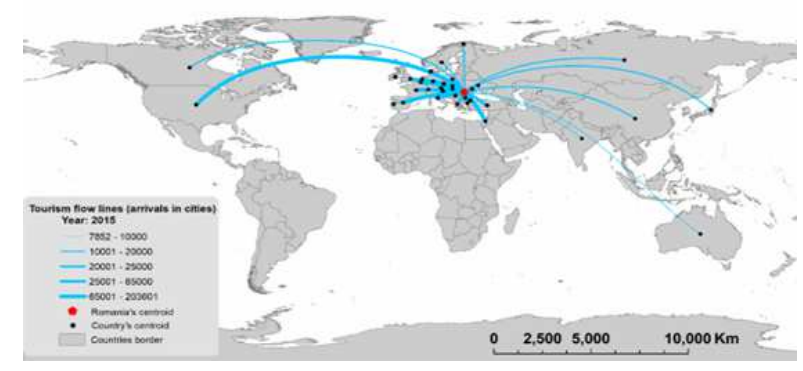

Fig. 1. (a) Arrivals of foreign tourists (2015) in the Romanian cities considering their country of origin. (b) Tourism flow lines (2015) from the origin countries to Romania. City tourism was considered for this analysis. Note: In this dataset, Tulcea City was not included.

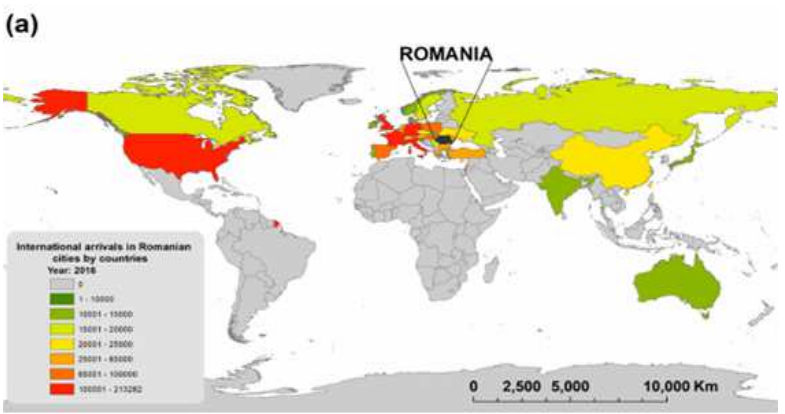

(b)

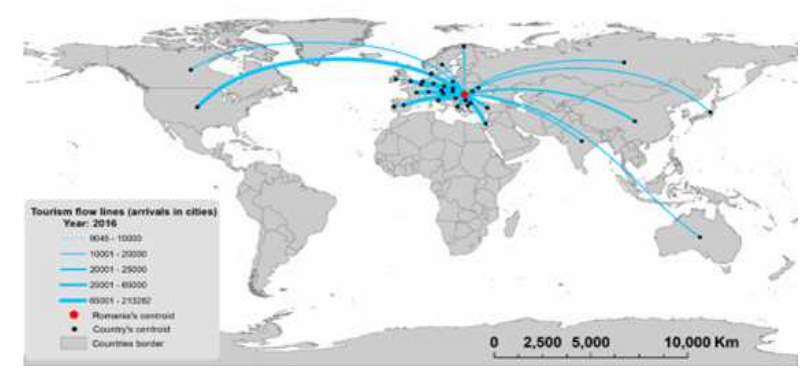

Fig. 2. (a) Arrivals of foreign tourists (2016) in the Romanian cities considering their country of origin. (b) Tourism flow lines (2016) from the origin countries to Romania. City tourism was considered for this analysis. Note: In this dataset, Tulcea City was not included. 
In 2016, the first three positions in the number of international arrivals, which had the city destinations in Romania, were assigned to Germany (213,282 arrivals), Israel (205,404 arrivals), and Italy (194,714 arrivals). Again, the European countries represent the main "source" of tourists to Romania. The countries represented by a low number of arrivals in Romania in 2016 were Denmark, Australia, and Slovenia, this year with a total number of arrivals of $10,818,10,388$, respectively 9,045. Figure 2a depicts the total international arrivals in the Romanian cities, by country. The result of the flow representation related to 2016 was mapped in Figure 2b.

The maximum recorded number of international arrivals in Romania in 2017 was represented by tourists from Germany (241,362 arrivals), Israel (237,850 arrivals) and Italy (195,413 arrivals). The low values of the international tourists for city visits refers to the same countries as in the previous year, but with higher values of arrivals (Demark: 12,672 arrivals, Australia: 12,518 arrivals, and Slovenia: 10,170 arrivals). Figure $3 \mathrm{a}$ illustrates the number of international arrivals in the Romanian cities, by country, for 2017. The result of flow representation related to 2017 was mapped in Figure $3 \mathrm{~b}$.
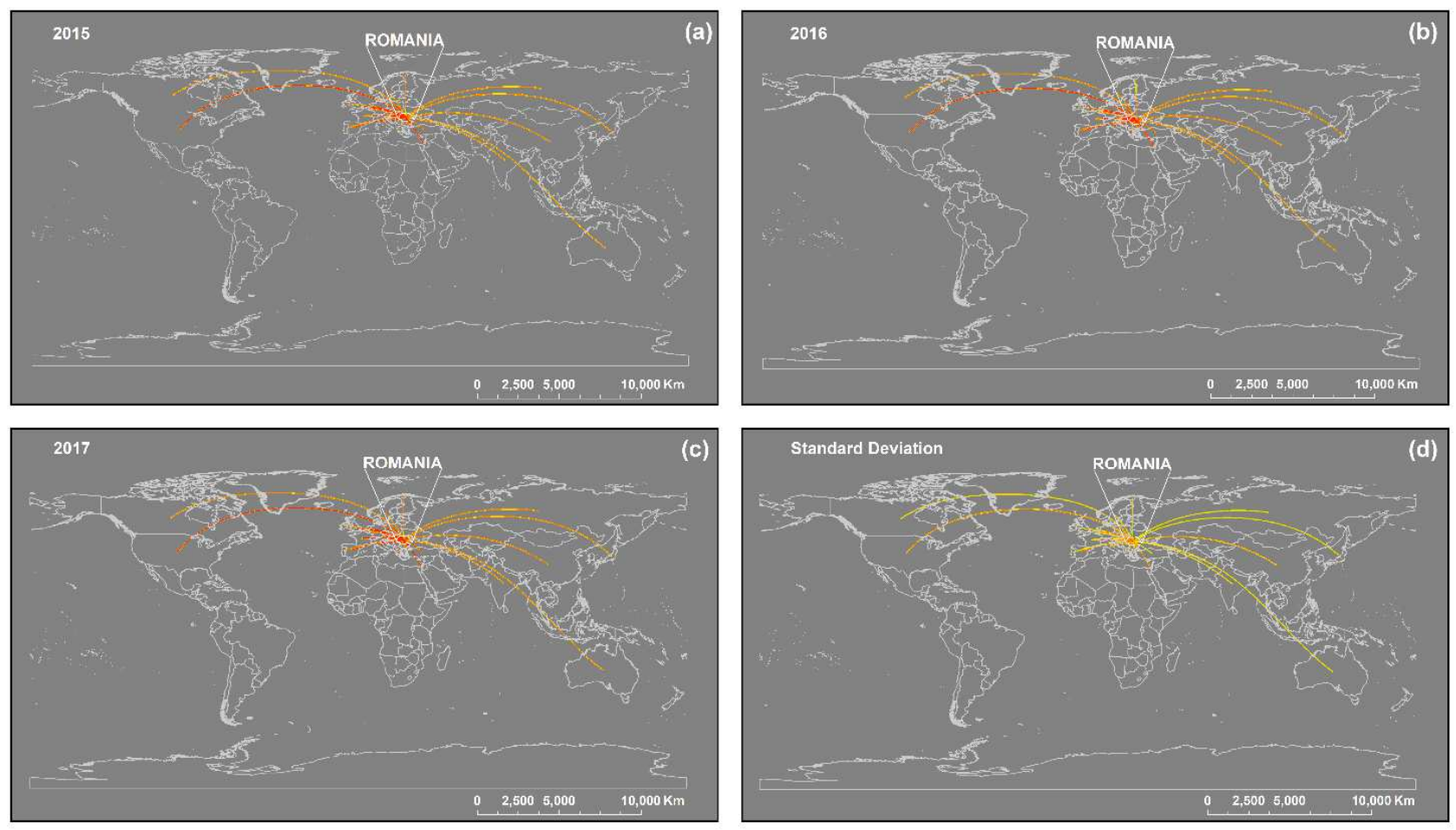

\begin{tabular}{|l|l|l|l|l|l|l|l|l|l|l} 
No Density & Very Low & Low & Medium & High & Very High \\
\hline
\end{tabular}

Fig. 4. Tourism flow over the Romanian cities. (a) Kernel Density related to 2015. (b) Kernel Density related to 2016. (c) Kernel Density related to 2017. (d) Standard deviation of Kernel Density in 2015, 2016, and 2017.

In all the three years analysed, the total number of tourists visiting the Romanian cities, exceeded 100,000 from the European and US countries.
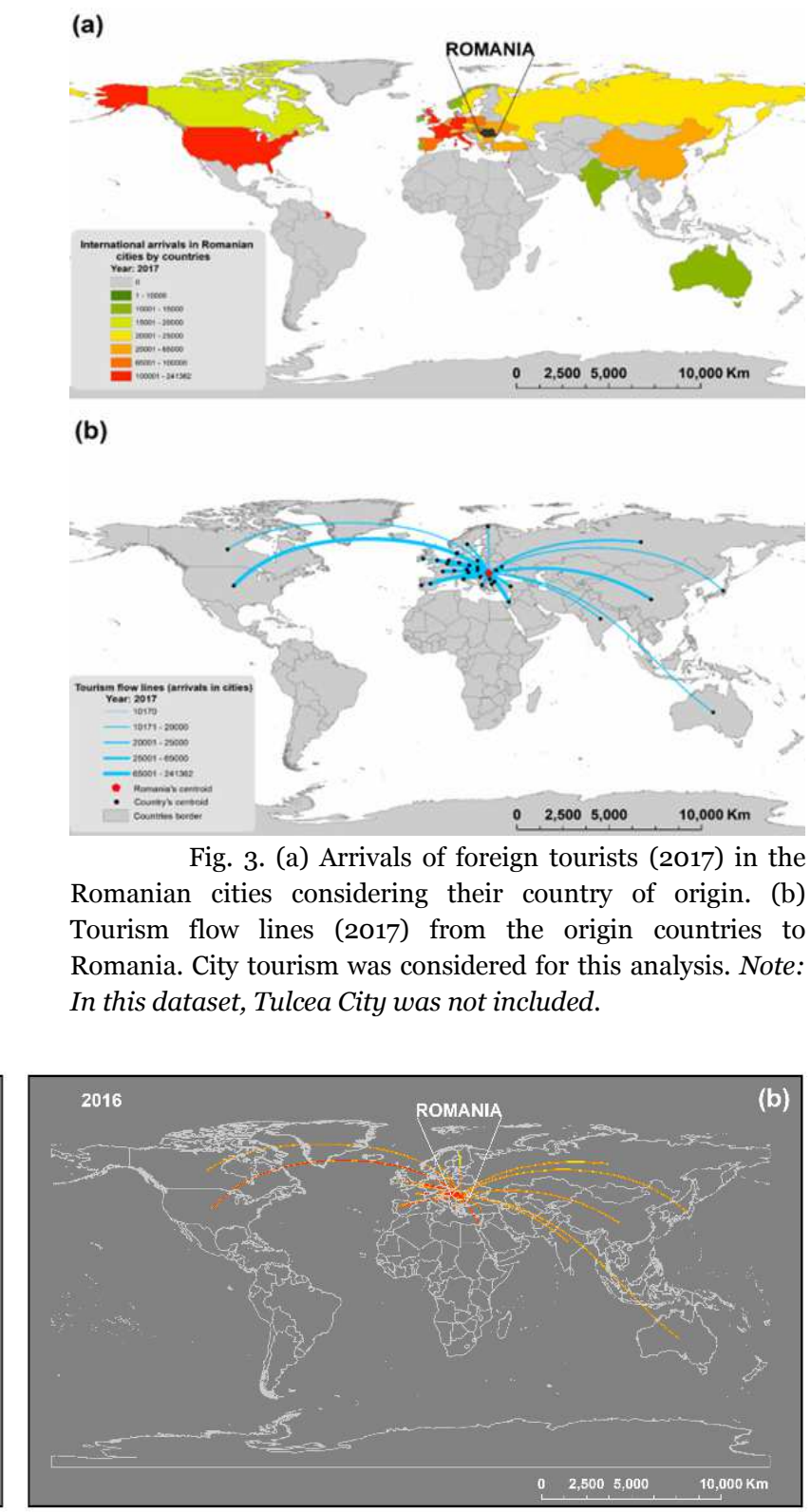

(b)

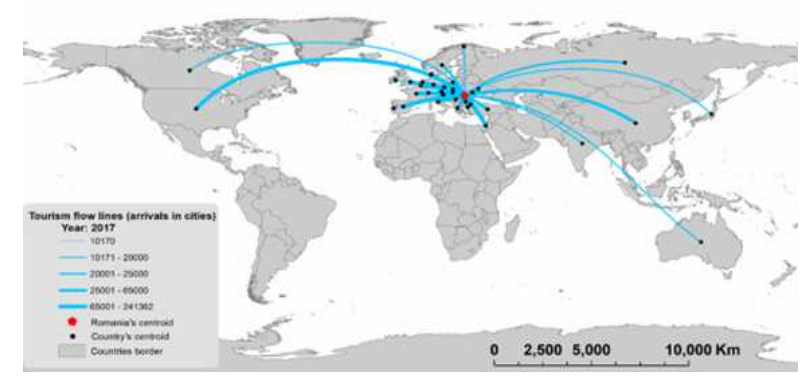

Fig. 3. (a) Arrivals of foreign tourists (2017) in the Romanian cities considering their country of origin. (b) Tourism flow lines (2017) from the origin countries to Romania. City tourism was considered for this analysis. Note: In this dataset, Tulcea City was not included.

d) 
Italy (Figures 5a-c). The standard deviation map (Fig. 4d) of Kernel Density for 2015-2017 period shows moderate density, with few exceptions such as China, US, Italy etc.

The combined map of the maximum density flow of tourists for 2015-2017 is shown in Figure 5. The high density (above 105) was found in central and western Europe, US, Turkey and Israel. The lower values of density (below $10^{2}$ ) were identified for the tourism flow lines of India and Australia.

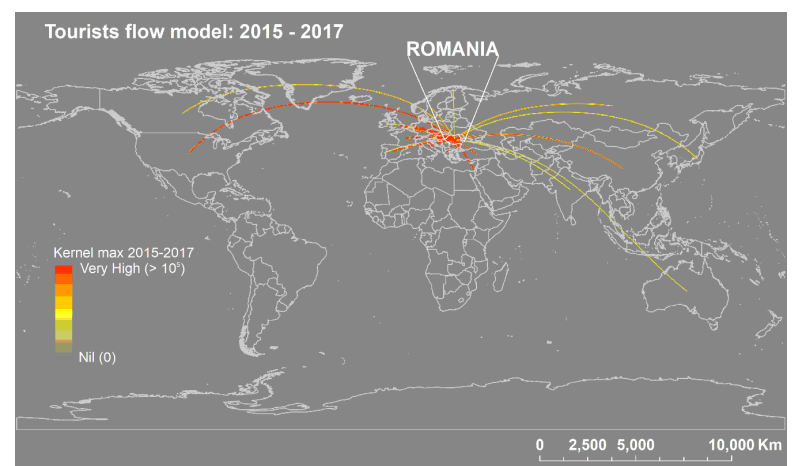

Fig. 5. Maximum tourism flow of the Kernel Density between 2015 and 2017.

During the period 2015-2017, the most obvious changes of Kernel Density at the spatial level were depicted in the Australia, US, India, China, Israel directions, but also over West Europe countries (Fig. $6 a)$. These are positive changes, showing increases up to $65 \%$. The negative changes were depicted over a few locations, including Ukraine. During 2016-2017, the high values of relative changes (37\%) are mostly representative for China, Australia, Spain, and Ireland (Fig. 6b).

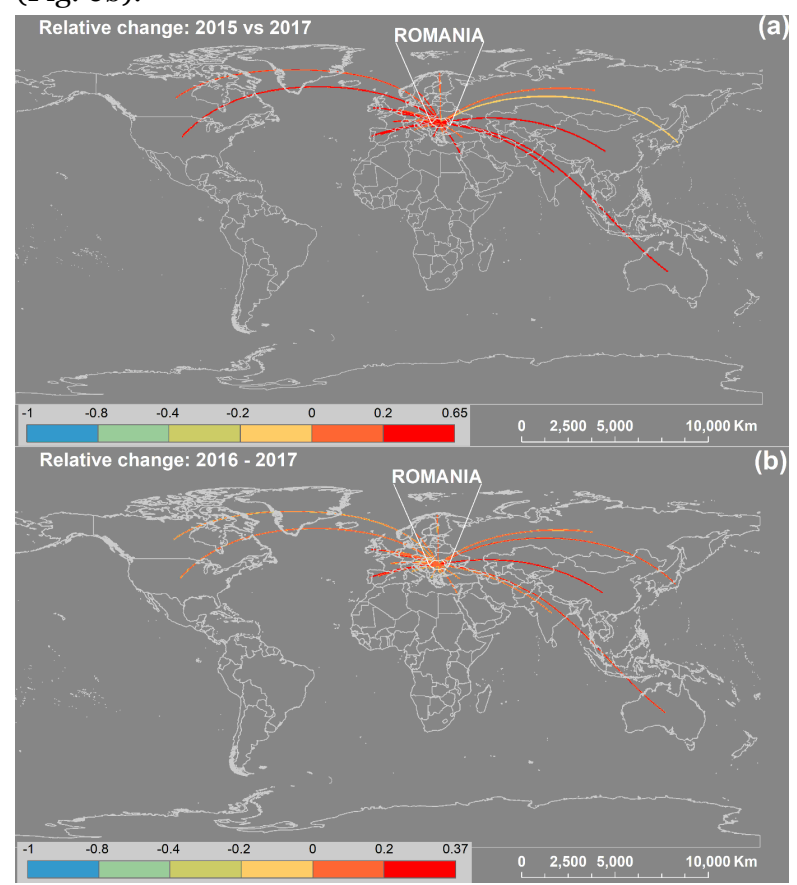

Fig. 6. Relative change of the tourism flow representation. (a) Changes between 2015 and 2017. (b) Changes between 2016 and 2017.
From the analysis of the density classes, it was observed that the very high class increased by $0.7 \%$ between 2015 and 2016 and by 1.7 between 2015 and 2017. The high class of density increased up to $1.39 \%$ between 2015 and 2017, while the medium, low, and very low classes decreased gradually during the period 2015-2017 (Table 1).

Table 1. Area of tourism flow density.

\begin{tabular}{l|rrr}
$\begin{array}{c}\text { Density } \\
\text { classes }\end{array}$ & $\begin{array}{c}\text { Density } \\
\text { classes for } \\
\mathbf{2 0 1 5} \text { (area } \\
\text { \%) }\end{array}$ & $\begin{array}{c}\text { Density } \\
\text { classes for } \\
\mathbf{2 0 1 6} \text { (area } \\
\text { \%) }\end{array}$ & $\begin{array}{c}\text { Density } \\
\text { classes for } \\
\mathbf{2 0 1 7} \\
\text { (area \%) }\end{array}$ \\
\hline Very low & 3.79 & 3.57 & 3.39 \\
Low & 6.03 & 5.76 & 5.34 \\
Medium & 19.12 & 18.42 & 17.13 \\
High & 53.78 & 54.24 & 55.17 \\
Very high & 17.27 & 18.01 & 18.96
\end{tabular}

Source: GIS statistics. Note: the values consider only the density for Romania, without nil values.

(a)

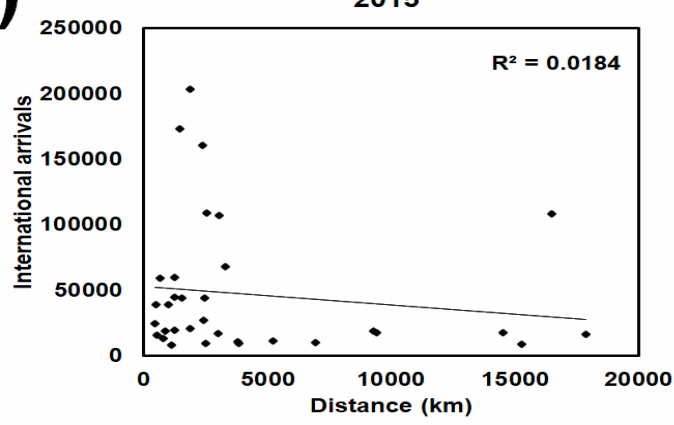

(b)

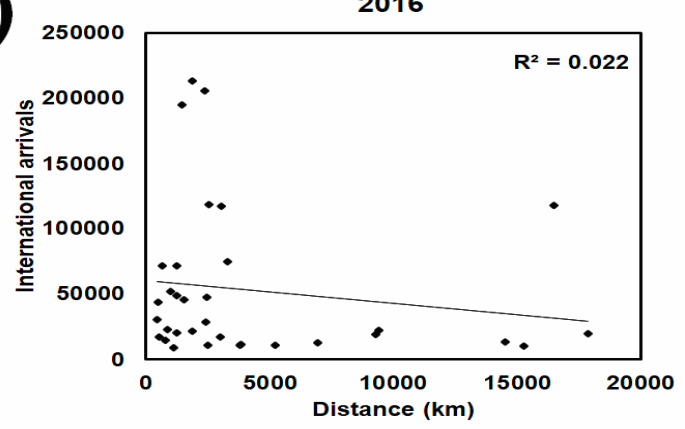

(c)

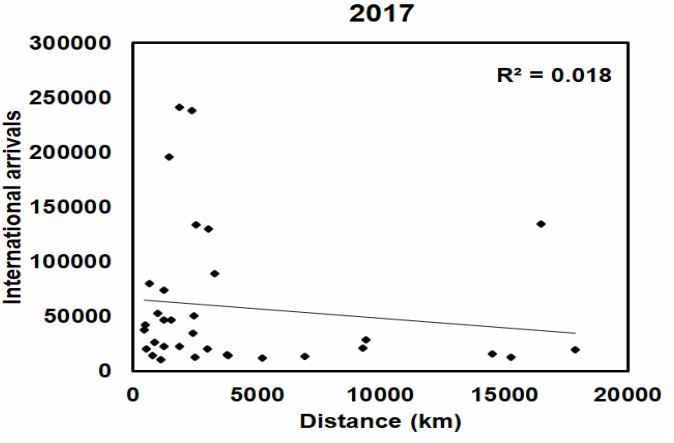

Fig. 7. Statistical analysis between the distance and the number of international arrivals in the Romanian cities. (a) Correlation related to 2015. (b) Correlation related to 2016. (c) Correlation related to 2017 . 
In fact, no correlation was found between the values of international arrivals in the Romanian cities and the distance from the origin country to Romania during the analysed period of 2015-2017 (Fig. 7).

In addition, the total number of departures and the distance from the origin countries to Romania for the 2015 and 2016 were collected and explored to find any relationship. Our findings indicate no correlation between the number of departures and the distance from the origin country to Romania (Fig. 8).

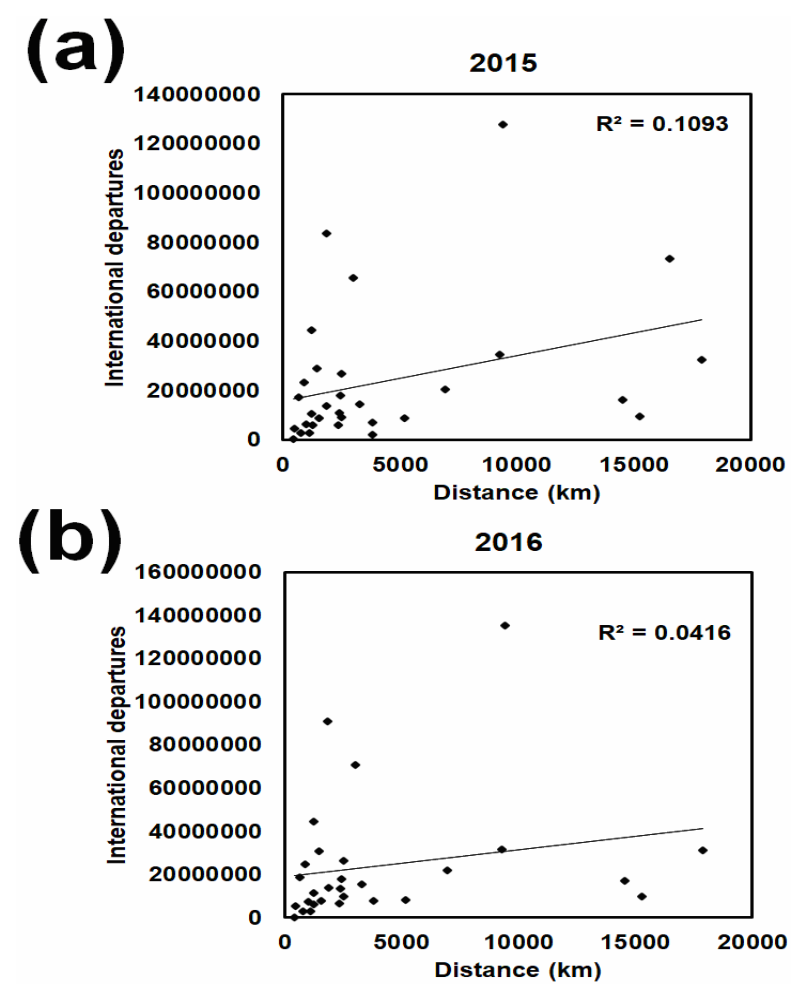

Fig. 8. Statistical analysis on the distance from the origin country and Romania and total departures from the origin country. (a) Correlation related to 2015. (b) Correlation related to 2016. Source: Worldbank, 2018.

The main aim of the paper was to propose a spatial flow representation approach for the international tourist arrivals in Romania. The current GIS Kernel Density map, that we presented, interchanges the temporal variation of international tourist arrivals in the Romanian cities during 2015-2017 with the spatial origin of tourists. Thus, using the " $\mathrm{XY}$ To Lines" function of the ArcGIS environment, the spatial representation of the maximum flow of tourists indicates that Germany is ranked first among origin countries of tourists in 2015. In 2016, the number of arrivals representing tourists from Germany increased by $5 \%$, while in 2017 , the maximum flow increased by $19 \%$. The total number of international arrivals in Romania with interest in visiting cities increased by 13\% between 2015 and 2016, while between 2015 to 2017 the increase was of about $25 \%$.

Based on our density map, the high city tourism demand for the Romanian cities was registered by tourists from the European countries and the US. However, these findings do not reach the tourism cities arrivals amount that France, Italy, and the US register in these years. This means that these countries, and not only, record a positive balance regarding the outcome/income of international tourists arrivals. Interestingly, South American and African countries are not listed in the countries with tourism city flow over Romania. This is due to the fact that tourists from these continents are really few or nonexistent in Romania.

Our proposed representation is a spatial approach to observe the tourists flow pattern from the origin country to the destination. The method combines both the distance and the number of international arrivals to generate the flow lines from different countries to Romania. In comparison with the statistical analysis, sometimes presented by trends analysis, simple charts, diagrams, or multivariate analysis, our approach gives an overview over the global situation of tourists and their movement to Romania. In addition, the relationship between tourist arrivals and distance from the origin country to Romania could be easily assessed by using GIS technology. Thus, the flow lines characteristics were calculated in the attributes of the features' lines. The exploration of tourism flows using GIS technology has many advantages such as: the opportunity to identify particular spatial behaviours or highlight destinations hotspots. The emergence of transport systems and the socioeconomic development of cities are contributing to the high increase of urban tourism flows. In this context, the GIS management of big data tourism flows becomes an imperative necessity, with the help of the automatic and validated tools.

The work is not without limitations, which may occur at spatial scale for the tourists that originated in other countries and were not registered in the database.

\section{CONCLUSIONS}

This work was focused on the analysis of tourism flow mapping using GIS applications. The approaches used here are based on both vector and raster data. By analyzing the mapping methods, the following conclusions could be drawn:

- the developed maps showed the density of the tourists' flow lines and analysed the changes between the considered years;

- the Kernel Density map contributes to the spatial representation of the tourism flow directions;

- the proceeding and application of tourism flow methodology was carried out for Romania using international arrivals related to city tourism;

- the statistics indicate that the central and southern part of Europe (Germany and Italy) and the Middle East (Israel) are the countries wherefrom a higher number of tourists $(674,625$ arrivals in 2017) are 
coming to Romania for city tourism (INS, 2017). Results show very high density of the tourism flow in the central and western part of Europe, US, Israel, and Turkey. High values of density were depicted for China and small countries from Europe.

This application represents a reliable approach with respect to the tourism literature and mapping of tourism flow. These findings could be useful for the tourism strategies in Romania, but also to observe the worldwide distribution of tourism flows over Romania. Based on the graphical representation of tourism flow developed in this paper, the plans regarding future tourism activities may consider the flow lines and density analysis of our study, as a framework and directive at spatial scale or Romania.

\section{REFERENCES}

Andraz J. M., Rodrigues P. M. M. (2016), Monitoring tourism flows and destination management: Empirical evidence for Portugal. Tourism Management 56, pp. 1-7. DOI: 10.1016/j.tourman. 2016.03. 019

Butler R. W. (1992), Alternative tourism: the thin edge of the wedge. In V. L. Smith, \& W. R. Eadington (Eds.), Tourism alternatives: potentials and problems in the development of tourism, pp. 302-321. Philadelphia: University of Pennsylvania Press

Carey S., Davidson L., Sahli M. (2013), Capital City Museums and Tourism Flows: an Empirical Study of the Museum of New Zealand Te Papa Tongarewa. International Journal of Tourism Research, 15 (6), pp. 554-569. DOI: https://doi.org/10.1002/jtr.1874

Fourie J., Santana-Gallego M. (2011), The impact of mega-sport events on tourist arrivals. Tourism Management, 32(6), pp. 1364-1370. DOI: 10.1016/ j.tourman.2011.01.011

Hall C. M., Page S. J. (2009), Progress in Tourism Management: From the geography of tourism to geographies of tourism - A review. Tourism Management, 30, pp. 3-16. DOI: 10.1016/j.tourman. 2008. 05.014

Hall C. M. (2012), Spatial analysis: A critical tool for tourism geographies. In J. Wilson (Ed.), The Routledge handbook of tourism geographies, pp. 163-173. London: Routledge.

Huang X., Zhang L., Ding Y. (2017), The Baidu Index: Uses in predicting tourism flows - A case study of the Forbidden City. Tourism Management 58, pp. 301-306. DOI: 10.1016/j.tourman.2016.03.015

Koenker R. (2005), Quantile Regression. Cambridge University Press, New York, NY 10011-4211, USA. ISBN 0-521-84573-4

INS (2017), Arrivals of foreign tourists, by country of residence and tourist areas. Published by Institutul Naţional de Statistică (National Institute of Statistics)
Retrieved from http://www.insse.ro/infrastructura statistică/metodologii. Accessed on October 20, 2018.

INS (2018), Arrivals of foreign tourists, by country of residence and tourist areas. Published by Institutul Naţional de Statistică. (National Institute of Statistics). Retrieved from http://www.insse.ro/infrastructura statistică/metodologii. Accessed on October 20, 2018.

Iațu C, Bulai M. (2011), New approach in evaluating tourism attractiveness in the region of Moldavia (Romania). International Journal of Energy and Environment 5(2), pp. 165-174.

Iorio M, Corsale A. (2010), Rural tourism and livelihood strategies in Romania. Journal of Rural Studies, 26, pp. 152-162. DOI: 10.1016/j.jrurstud.2009. 10.006

Jin X. C., Qu M., Bao J. (2019), Impact of crisis events on Chinese outbound tourist flow: A framework for post-events growth. Tourism Management 74, pp. 334-344. DOI: 10.1016/j.tourman.2019.04.011

Light D. (2010), An Unwanted Past: contemporary tourism and the heritage of communism in Romania. International Journal of Heritage Studies, 6(2), pp. 145160. DOI: https://doi.org/10.1080/135272500404197

Light D., Dumbrăveanu D. (1999), Romanian Tourism in the Post-Communist Period. Annals of Tourism Research, 26(4), pp. 898-927. DOI: https://doi.org/10.1016/So16o-7383(99)00033-X

Liu P, Zhang H, Zhang J, Sun Y, Qiu M. (2019), Spatial-temporal response patterns of tourist flow under impulse pre-trip information search: From online to arrival. Tourism Management 73, pp. 105-114. DOI: 10.1016/j.tourman.2019.01.021

Marrocu E, Paci R. (2011). They arrive with new information. Tourism flows and production efficiency in the European regions. Tourism Management 32, pp. 750-758. DOI: 10.1016/j.tourman.2010.06.010

Pomeanu E. E., Teodosiu C. (2012), Assessment of Tourism Development in Romania: Environmental Issues and Challenges in North of Moldova. Environmental Engineering and Management Journal, 11(2), pp. 439-447.

Santeramo F. G. (2015), Promoting the international demand for agritourism: Empirical evidence from dynamic panel. Tourism Economics. DOI:10.5367/ te.2014.0397

Santeramo F. G., Morelli A. (2016), Modelling tourism flows through gravity models: a quantile regression approach. Current Issues in Tourism, 19(11), pp. 1077-1083. DOI: https://doi.org/10.1080/ 13683500.2015.1051518

Silverman B. W. (1986), Density Estimation for Statistics and Data Analysis. Published by Chapman and Hall, New York, US.

Xing-zhu Y., Qun W. (2013), Exploratory Spacetime Analysis of Inbound Tourism Flows to China Cities. International Journal of Tourism Research, 16 (3), pp. 303-312. DOI: 10.1002/jtr.1932 
Yang Y, Wong K. K. F. (2012), A Spatial Econometric Approach to Model Spillover Effects in Tourism Flows. Journal of Travel Research, 51(6), pp. 768-778. DOI: https://doi.org/10.1177/0047287512437855

World Travel and Tourism Council (2006), Romania - The Impact of Travel \& Tourism on Jobs and the Economy. Sovereign Court. London E1W 3HA, United Kingdom.
World Travel and Tourism Council (2018), Travel \& Tourism Economic Impact 2018 Romania. London SE1 oHR, United Kingdom.

Zieba M. (2016), Tourism flows and the demand for regional and city theatres in Austria. Journal of Cultural Economics, 40(2), pp. 191-221. 